\title{
Leveraging Simulation Tools to Deliver Ill-Structured Problems in Statics and Mechanics of Materials: Initial Results
}

\section{Prof. Christopher Papadopoulos, University of Puerto Rico, Mayaguez Campus}

Christopher Papadopoulos is an Assistant Professor in the Department of General Engineering at the University of Puerto Rico, Mayagüez (UPRM). He earned B.S. degrees in Civil Engineering and Mathematics from Carnegie Mellon University (1993) and a Ph.D. in Theoretical \& Applied Mechanics at Cornell University (1999). Prior to coming to UPRM, Papadopoulos served on the faculty in the Department of Civil Engineering \& Mechanics at the University of Wisconsin-Milwaukee (UWM).

Papadopoulos has diverse research and teaching interests in structural mechanics, biomechanics, appropriate technology, engineering ethics, and engineering education. He serves as Secretary of the ASEE Mechanics Division and serves on numerous committees at UPRM that relate to undergraduate and graduate education.

\section{Aidsa Ivette Santiago Roman, University of Puerto Rico, Mayaguez Campus}

Aidsa I. Santiago-Román is a Tenured Assistant Professor in the General Engineering Department at the University of Puerto Rico, Mayaguez Campus (UPRM). Dr. Santiago earned a BA and MS in Industrial Engineering from UPRM and Ph.D in Engineering Education from Purdue University. Before attending Purdue University, she has been an engineering instructor for about 10 years. Her primary research interests are investigating students' understanding of difficult concepts in engineering science, especially for underrepresented populations and she also works in the implementation of best practices at UPRM.

\section{Dr. Genock Portela-Gauthier, University of Puerto Rico, Mayaguez Campus}

Genock Portela is an Associate Professor in the Department of General Engineering at the University of Puerto Rico, Mayaguez. He earned a Ph.D. degree in structural engineering at the University of Puerto Rico, Mayaguez (2004). Portela has primary research and teaching interests in structural mechanics, mostly oriented to bridge engineering. At UPRM College of Engineering, Portela serves as Special Assistant to the Dean.

\section{Prof. Arturo Ponce, University of Puerto Rico-Mayaguez}

Arturo Ponce has a BS in Computer Engineering and a MS in Electrical Engineering from UPR Mayaguez. $\mathrm{He}$ is an associate researcher at the UPR Mayaguez School of Engineering where he has done institutional research work since 2003. He worked in the ABET Accreditation process for the School of Engineering from 2003 to 2012 . 


\section{Leveraging Simulation Tools to Deliver Ill-Structured Problems in Statics and Mechanics of Materials: Initial Results}

\section{Introduction}

This paper reports initial results after the first semester of implementation of a TUES project during the Fall 2012 semester at the University of Puerto Rico Mayagüez (UPRM). This project introduces new modules in Statics and the subsequent course of Mechanics of Materials that are designed to accomplish the following three goals simultaneously:

- Accelerate development of student design expertise

- Develop simulation competency

- Advance use of longitudinal assessment to determine efficacy

We seek to accomplish these goals by introducing ill-structured problems into the Statics and Mechanics of Materials courses. By "ill-structured" we mean problems that require students to evaluate or provide assumptions, investigate appropriate background information, compare several "what if" scenarios, or otherwise perform design or design-related tasks. Such problems differ in at least some manner from "well-structured" problems that are typified by textbook problems that provide students with all of the requisite information and only this information, that possess unique solutions, and which can be done on pencil \& paper.

Engineering design problems are by nature ill-structured, but the curriculum remains dominated by courses and textbooks that feed students a steady diet of well-structured problems. Whether engineering educators consciously believe that expertise in well-structured "building block" problems automatically translates into expertise in ill-structured (design) problems is perhaps an open question, but several leading education researchers challenge this assumption and argue that direct experience with ill-structured problems throughout the curriculum is necessary in order to build expertise in activities such as engineering design ${ }^{1-6}$. We further note that illstructured problems provide opportunities for students to anticipate topics from subsequent courses and allow for smooth vertical integration; we adopt this approach here.

The incorporation of simulation tools is important for its own sake and as reviewed in Papadopoulos et al. has several prior precedents ${ }^{7}$. But use of simulation tools can amplify the effectiveness of ill-structured engineering problems, particularly when a design question requires several computations that are either tedious or too numerous to effectively do by hand. We further believe that simulation tools can be meaningfully introduced to entry level students in a manner that does not require them to understand the underlying computational theory of the tool, but in a manner that can enable them to interpret results more maturely ${ }^{8}$.

We note that the target cohort of this study is students in the Civil Engineering degree program. A reason for selecting a specific cohort is so we can track student progress longitudinally along a "curricular strand", which is a set of consecutive courses within a major. Although our 
interventions will take place only in Statics and Mechanics of Materials I, we will measure student progress in the subsequent courses Mechanics of Materials II and Structural Analysis to assess the lasting effectiveness of our approach.

\section{Description of New Course Modules}

Several experts both at our institution and at others were polled as to what types of issues and problems are important to address in the mechanics courses for students in the Civil Engineering/Structural Engineering track. Based on their responses and on practical issues, we developed three new modules, summarized as follows:

- Module 1: Slope of Road. In this module, assigned during Week 1, students were asked to determine the slope of a road on campus that is considered steep. This was designed to serve as a review of basic trigonometry and to introduce students to an ill-structured problem in which they were left to determine the methodology and how to interpret their results correctly. We viewed that prior knowledge of students was sufficient to undertake this modules with a minimum of explanation. A photo of the road is shown in Figure 1.

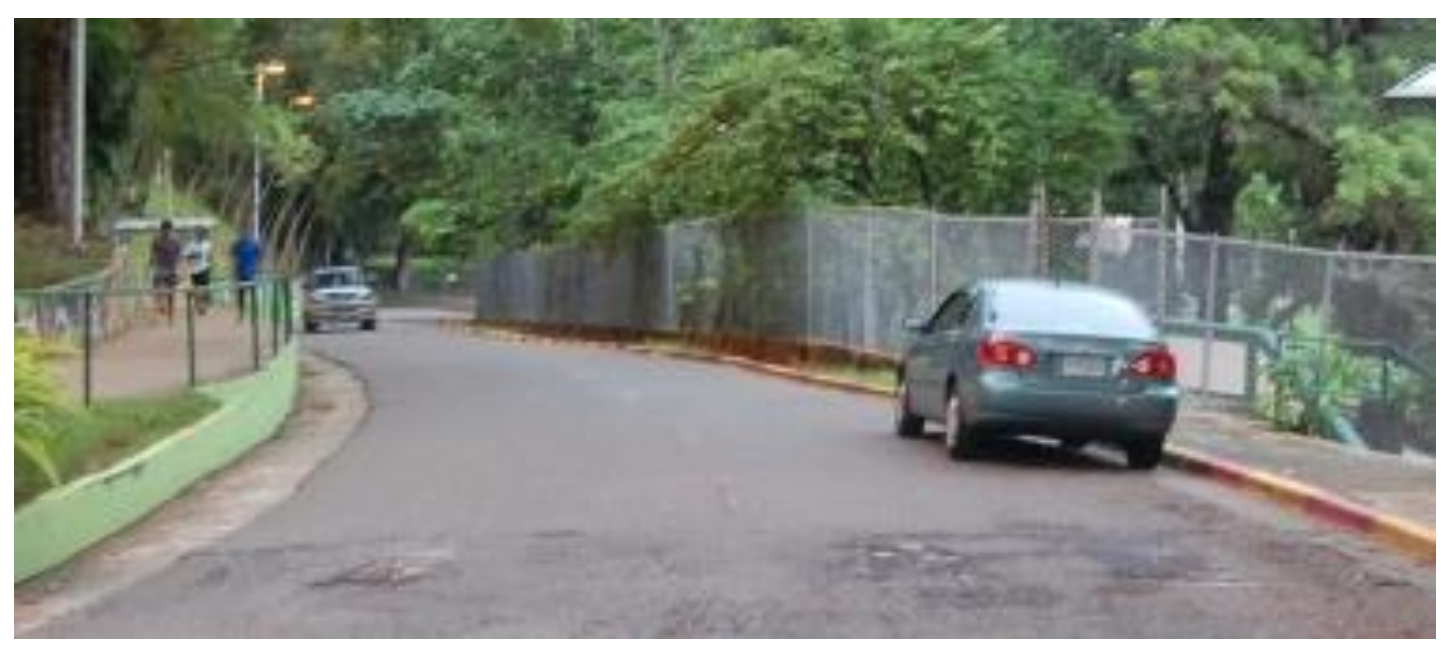

Figure 1. Photo of Road for Module 1.

- Module 2: Redundant Three-bar Structure. In this module, which was assigned in Week 6 (after a basic introduction to force equilibrium), students were provided with the problem of a weight hanging from a joint at which are joined three truss members (2-dimensional system), as shown in Figure 2. 


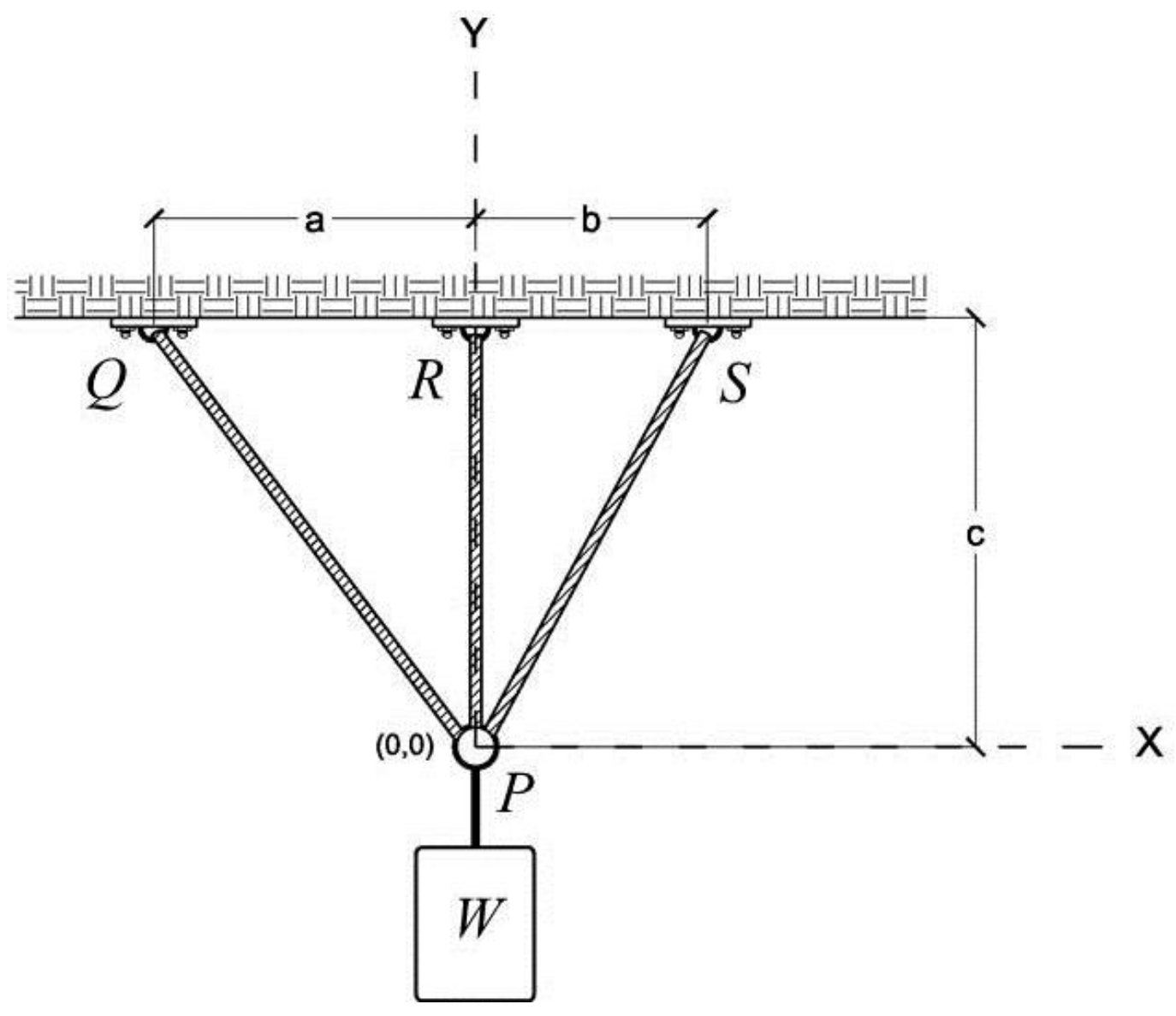

Figure 2. Sketch of Three-bar Redundant Truss

At its basic level, this module required students to look up the elastic modulus of the given material, determine the displacement of the joint, and determine the force carried by each member. At is deeper level, students were asked to investigate changes in these behaviors based on changes in geometry and material.

Such a problem is usually not presented in a statics course because the topics of elasticity, displacement, and redundancy are presented in Mechanics of Materials. However, under our approach, we provided the students with a tutorial that provided the equations of compatibility and translated the typical bar stiffness $E A / L$ into and equivalent spring stiffness $k$, which is familiar to Statics students. Students were then asked to enter parameters into a prepared Excel Spreadsheet that would enable them to solve for the displacement of the joint and subsequently the forced in each member. Figure 3 shows an annotated image of the spreadsheet that students can use to solve the problem. 


\begin{tabular}{|c|c|c|c|c|c|c|c|c|}
\hline \multicolumn{9}{|c|}{ Parameters } \\
\hline & $10^{3} \mathrm{ksi}$ & & in & & in & & & \\
\hline E_PQ & 29.0 & d_PQ & 0.50 & a & 16.00 & & & \\
\hline E_PR & 29.0 & d_PR & 0.50 & b & 12.00 & & & \\
\hline \multirow[t]{2}{*}{ E_PS } & 29.0 & d_PS & 0.50 & c & 12.00 & & & \\
\hline & k/in & & deg & & in & & & \\
\hline k_PQ & 284.7 & $\theta \_P Q$ & 143.1 & L_PQ & 20.00 & & & \\
\hline k_PR & 474.5 & $\theta \_$PR & 90.0 & L_PR & 12.00 & & & \\
\hline \multirow[t]{2}{*}{ k_PS } & 335.5 & $\theta \_$PS & 45.0 & L_PS & 16.97 & & Results & \\
\hline & & & & & & & F_PQ & 1.288 \\
\hline \multicolumn{2}{|c|}{ Equation Table } & & & & & & F_PR & 3.197 \\
\hline & $\delta \_P Q$ & 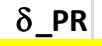 & $\delta \_$PS & $\delta \_x$ & $\delta \_y$ & load & F_PS & 1.457 \\
\hline Sum Fx & -227.8 & 0.0 & 237.3 & 0.000 & 0.000 & 0.00 & $\delta \_P Q$ & 0.0045 \\
\hline Sum Fy & 170.8 & 474.5 & 237.3 & 0.000 & 0.000 & 5.00 & d_PR & 0.0067 \\
\hline $\mathrm{C} 1$ & 1.00 & 0.00 & 0.00 & -0.800 & 0.600 & 0.00 & $\delta \_P S$ & 0.0043 \\
\hline C2 & 0.00 & 1.00 & 0.00 & 0.000 & 1.000 & 0.00 & $\delta \_x$ & 0.0006 \\
\hline C3 & 0.00 & 0.00 & 1.00 & 0.707 & 0.707 & 0.00 & $\delta \_y$ & -0.0067 \\
\hline
\end{tabular}

Figure 3. Spreadsheet corresponding to Module 2. Students enter parameter values at the top and then enter coefficients into a matrix that will solve the equilibrium and compatibility equations. Green = manual entry of given data; Yellow = calculated value from a given formula; Red = research or interpretation required; Gray = automatic output. Green-Red fade: manual entry becomes interpretive when doing a 'what if' scenario in which students need to vary parameters in order to understand trends in system behavior.

- Module 3: Design of a Steel Signpost. In this module, which was assigned in Week 12 (after students had completed the study of rigid body static equilibrium in 3 dimensions), students were asked to investigate how to determine the size - particularly the inner and outer diameters - of a steel signpost that supports a billboard, within given limits of size and allowable stress. The other geometric dimensions (height of sign, width of sign, etc.) were given, as were estimates of loads due to weight and wind. Figure 4 illustrates the basic model. Again, such a problem is beyond the traditional statics curriculum because it requires at least basic analysis of stress at the base of the post. But under our approach, we provided the students with a simple tutorial introducing the concept of stresses (due to axial, bending, lateral shear, and torsion), and a prepared spreadsheet that calculated the required stresses at the base. 


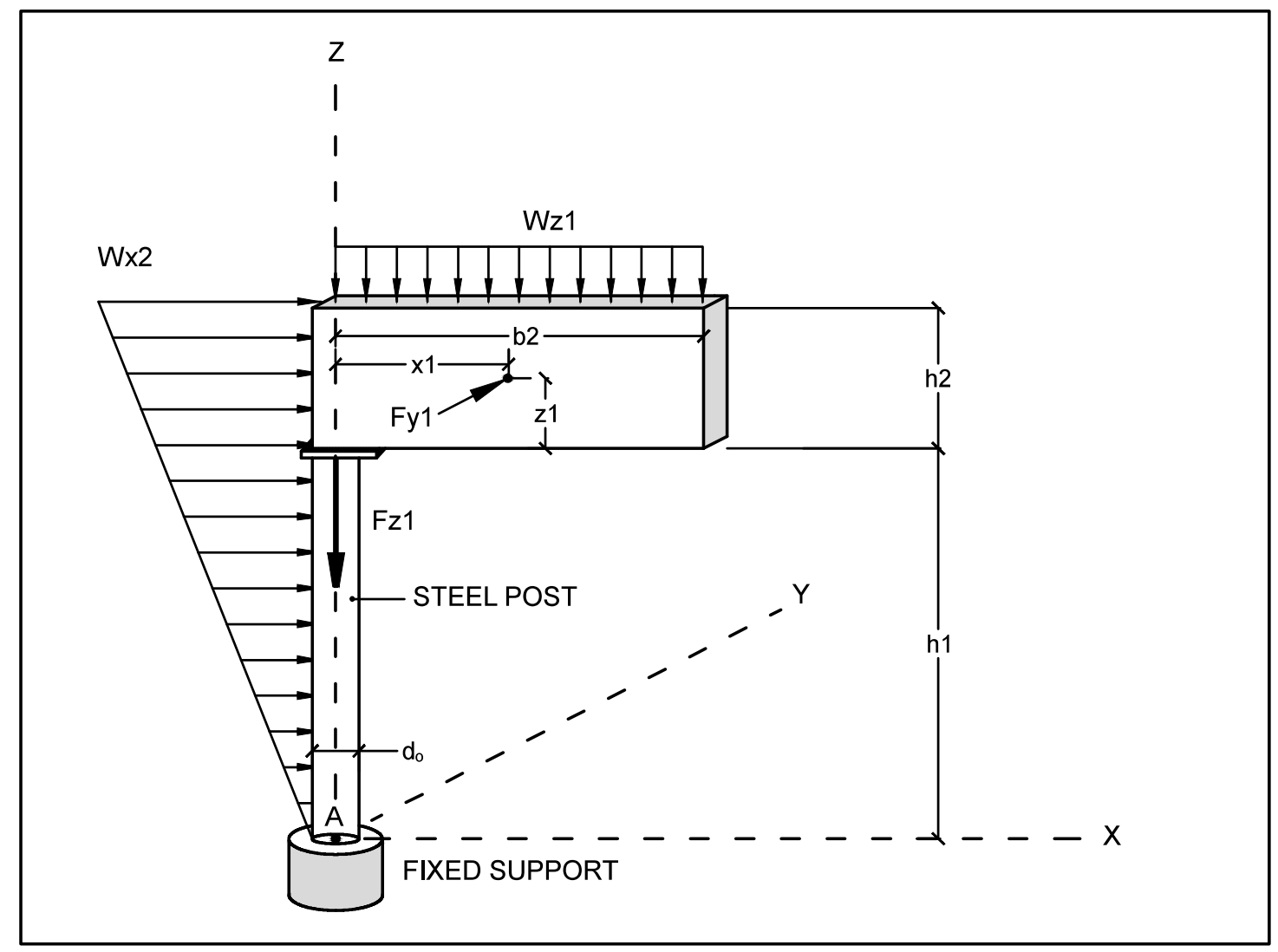

Figure 4. Illustration of Signpost and Billboard for Module 3.

Students were asked to first determine the reactions at the base of the signpost (by both including and excluding the weight of the signpost itself) using completely traditional static equilibrium equations. These reactions were then to be entered or directly calculated in specific cells within the prepared Excel spreadsheet. Students could then enter test values of inner and outer diameter of the post. Once the reactions and trial dimensions were entered, four stress quantities were automatically calculated: normal stress due to axial load; normal stress due to bending; shear stress due to lateral force; and shear stress due to torsion. By comparing the resulting stresses with allowable limits, students were asked to recommend a size of the pole. However, they are also asked to consider whether any other factors, such as size or weight, would also influence their choice of design. Additional questions were asked to probe their understanding, such as why a solid post is not used, why it is (apparently) sufficient to study stress at the base of the pole an nowhere else, and which load(s) is (are) most influential in driving the design (including, in particular, whether the weight of the post itself is significant in this sense). Figure 5 shows an annotated image of the spreadsheet that student can use for Module 3. 


\begin{tabular}{|c|c|c|c|c|c|c|c|c|c|c|c|}
\hline & & & & & & wind $x$ & wind $y$ & wt sign & & & \\
\hline Param & $x 1$ & $\mathrm{z1}$ & b2 & h1 & h2 & $W \times 2$ & Fy1 & Wz1 & $\gamma$ Steel & & \\
\hline Units & $\mathrm{ft}$ & $\mathrm{ft}$ & $\mathrm{ft}$ & $\mathrm{ft}$ & $\mathrm{ft}$ & $\mathrm{k} / \mathrm{ft}$ & $\mathbf{k}$ & $k / f t$ & $\mathrm{k} / \mathrm{ft}^{\wedge} 3$ & & \\
\hline Value & 6 & 4 & 13 & 28 & 8 & 0.70 & 8.00 & 0.90 & 0.49 & & \\
\hline Units & in & in & in & in & in & k/in & $\mathrm{n} / \mathrm{a}$ & $\mathrm{k} / \mathrm{in}$ & $\mathrm{k} / \mathrm{in}^{\wedge} 3$ & & \\
\hline Value & 72 & 48 & 156 & 336 & 96 & 0.0583 & $n / a$ & 0.0750 & 0.00028 & & \\
\hline Reactions & Vx $=A x$ & $\mathrm{Vy}=\mathrm{Ay}$ & Vresult & $P=A z$ & Mx & My & Mresult & $\mathrm{T}=\mathrm{Mz}$ & & & \\
\hline Units & kip & kip & kip & kip & kip*in & kip*in & kip*in & kip*in & & & \\
\hline Value & -12.6 & -8.00 & 14.93 & 11.70 & 3072 & -4541 & 5483 & -576 & & & \\
\hline Property & $d_{0}$ & $d_{i}$ & $t$ & $\mathbf{A}$ & IX & $\mathrm{J}$ & C & Wt Post & & & \\
\hline Units & in. & in. & in. & in. $^{2}$ & in. $^{4}$ & in. $^{4}$ & in. & kip & & & \\
\hline Value & 28.25 & 27.50 & 0.375 & 32.84 & 3190 & 6380 & 14.13 & 4.02 & & & \\
\hline Stress & $\sigma_{\text {axial }}$ & $\sigma_{\text {bend }}$ & $\max \sigma_{z}$ & Allow & Summary & $d_{0}$ & $d_{i}$ & $t$ & $\max \sigma_{z}$ & $\max \tau$ & Wt Post \\
\hline Units & ksi & ksi & ksi & ksi & & in. & in. & in. & ksi & ksi & kip \\
\hline Value & 0.36 & 24.28 & 24.63 & 25 & Hollow1 & 34.25 & 33.75 & 0.250 & 24.77 & 2.40 & 3.27 \\
\hline Stress & $\tau_{\text {lateral }}$ & $\tau_{\text {torsion }}$ & $\max \tau$ & Allow & Hollow2 & 28.25 & 27.50 & 0.375 & 24.63 & 2.18 & 4.02 \\
\hline Units & ksi & ksi & ksi & ksi & Hollow3 & 24.75 & 23.75 & 0.500 & 24.53 & 2.06 & 4.67 \\
\hline Value & 0.91 & 1.28 & 2.18 & 16 & Hollow4 & 22.50 & 21.00 & 0.625 & 24.83 & 1.99 & 5.20 \\
\hline & & & & & Solid & 14.25 & 0.00 & 7.125 & 24.23 & 1.26 & 19.54 \\
\hline
\end{tabular}

Figure 5. Spreadsheet corresponding to Module 3. Students enter parameter values, then calculate reactions at the base, then enter trial values for inner and outer diameter, then read stresses at the base. Green = manual entry of given data; Yellow = calculated value from a given formula; Red = research or interpretation required; Gray = automatic output. Green-Red fade: manual entry becomes interpretive when doing a 'what if' scenario in which students need to vary parameters to understand trends in system behavior. Gray-

Red fade: reading automatic output becomes interpretive when selecting a design.

Table 1 summarizes the content and attributes of the three modules.

\begin{tabular}{|l|l|l|l|l|l|}
\hline \multicolumn{2}{|l|}{ Table 1. Content and attributes of the three modules introduced in Statics during Fall 2012.} \\
\hline Module Title & Weeks & $\begin{array}{l}\text { Traditional } \\
\text { Statics Topics }\end{array}$ & $\begin{array}{l}\text { Mechanics of Materials } \\
\text { Topics Integrated }\end{array}$ & $\begin{array}{l}\text { Simulation } \\
\text { Tool Required }\end{array}$ & Ill-structured Attributes \\
\hline $\begin{array}{l}\text { 1. Slope of } \\
\text { Road }\end{array}$ & $1-2$ & Trigonometry & None & None & $\begin{array}{l}\text { Select methodology of } \\
\text { determining slope; correctly } \\
\text { verify or interpret answer; } \\
\text { recognize or comment on } \\
\text { possible errors in method }\end{array}$ \\
\hline $\begin{array}{l}\text { 2. Redundant } \\
\text { Structure }\end{array}$ & $6-8$ & $\begin{array}{l}\text { Force Equilibrium } \\
\text { of Particle }\end{array}$ & $\begin{array}{l}\text { Axial displacement; use } \\
\text { of approximations to } \\
\text { compute displacements; } \\
\text { analysis of redundant } \\
\text { structure }\end{array}$ & $\begin{array}{l}\text { Excel } \\
\text { Spreadsheet }\end{array}$ & $\begin{array}{l}\text { Look up E for steel and } \\
\text { aluminum; estimate for bungee } \\
\text { cord; correctly sense order of } \\
\text { magnitude of solution; vary } \\
\text { parameters in spreadsheet to } \\
\text { see system behavior }\end{array}$ \\
\hline $\begin{array}{l}\text { 3. Steel } \\
\text { Signpost }\end{array}$ & $13-16$ & $\begin{array}{l}\text { Force and } \\
\text { moment reactions } \\
\text { in 3D, including } \\
\text { as caused by } \\
\text { distributed loads }\end{array}$ & $\begin{array}{l}\text { Stress analysis; failure } \\
\text { stress and factor of } \\
\text { safety }\end{array}$ & $\begin{array}{l}\text { Excel } \\
\text { Spreadsheet }\end{array}$ & $\begin{array}{l}\text { Look up unit weight of steel; } \\
\text { vary parameters in } \\
\text { spreadsheet to see system } \\
\text { behavior; iterative use of } \\
\text { spreadsheet to arrive at } \\
\text { design. }\end{array}$ \\
\hline
\end{tabular}




\section{Initial Results from Fall 2012 Statics Intervention}

The three new course modules were delivered in three sections of Statics, two taught by one of the authors, and one taught by another of the authors. At total of 146 students were enrolled, with 49 being in the target population of Civil Engineering. Table 2 provides a summary of the pre-course profile and performance data of the students.

\begin{tabular}{|c|c|c|c|c|c|c|c|c|}
\hline Cohort & $\mathrm{N}$ & $\begin{array}{r}\text { Avg GPA } \\
\text { prior to } \\
\text { Fall } 2012 \\
\text { semester } \\
\text { Max }=4\end{array}$ & $\begin{array}{r}\text { Avg grade in } \\
\text { Calculus l: } \\
\text { first attempt } \\
\text { Max }=4\end{array}$ & $\begin{array}{r}\text { Avg Grade } \\
\text { in Statics } \\
\text { Fall } 2012 \\
\text { Max }=4\end{array}$ & $\begin{array}{r}\text { Avg } \\
\text { Grade in } \\
\text { Module } \\
\text { Statics } \\
\text { Fall } 2012 \\
\text { Max }=10\end{array}$ & $\begin{array}{r}\text { Avg Score } \\
\text { on CATS } \\
\text { post test } \\
\text { Fall } 2012 \\
\text { Max }=27 \\
\text { (number of } \\
\text { takers) }\end{array}$ & $\begin{array}{r}\text { Received C } \\
\text { or higher in } \\
\text { Statics Fall } \\
2012 \text { AND } \\
\text { passed } \\
\text { Calculus II } \\
\text { prior to } \\
\text { Spring } 2013\end{array}$ & $\begin{array}{r}\text { Enrolled in } \\
\text { Target } \\
\text { Section of } \\
\text { MoM I } \\
\text { Spring } \\
2013\end{array}$ \\
\hline All & 146 & 2.75 & 1.24 & 1.51 & 6.64 & $8.72(89)$ & $\mathrm{n} / \mathrm{a}$ & $\mathrm{n} / \mathrm{a}$ \\
\hline Civil Eng & 49 & 2.68 & 0.92 & 1.22 & 6.68 & $8.47(30)$ & 15 & 7 \\
\hline Mech Eng & 38 & 3.03 & 1.84 & 2.16 & 6.95 & $10.39(28)$ & $n / a$ & $\mathrm{n} / \mathrm{a}$ \\
\hline Not CE or ME & 59 & 2.64 & 1.10 & 1.32 & 6.40 & $7.45(31)$ & $\mathrm{n} / \mathrm{a}$ & $n / a$ \\
\hline
\end{tabular}

Although not part of the target population of this study, Table 2 includes a separate description of the students in Mechanical Engineering because of the stark difference in performance between this cohort and all other students. We have since learned that this is not an aberration in our data; rather, over the last decade, students entering Mechanical Engineering have a significantly stronger academic profile than students entering other majors in our College of Engineering.

Table 2 also reveals that of the 49 students in the target Civil Engineering cohort, only 15 completed the course with a $\mathrm{C}$ or better AND with a passing grade in Calculus II, which is also a prerequisite for Mechanics of Materials I. Of these 15 students, only 7 continued into the targeted section of Mechanics of Materials for Spring 2013. A primary reason for the large number of qualified students declining to continue was due to conflicts with other courses.

It is difficult to assign absolute meaning to the course grade. One problem is that the average assessed grade varies widely from instructor to instructor. The average assessed grade by the authors teaching the targeted sections is somewhat below their own historical averages over the last few semesters, but this could be dominated by the fact that the incoming grade point average and average grade in Calculus I of the Fall 2012 students was also lower than for our own students in recent semesters. 
The scores on the Concept Assessment Tool for Statics (CATS) [cihub.org] are similar to recent trends at our campus. Grades in Statics and scores on the CATS correlate somewhat positively with the students' prior background, i.e., their overall GPA and their grade in Calculus I (the determination of a strict quantification of this relationship is still in progress). At the end of the Fall 2012 semester, 12 students from Civil Engineering who were not in the targeted sections also took the CATS. Both the average score and GPA of these students $(10.27,2.96)$ was higher than the average score and GPA of the students in the targeted sections $(8.47,2.68)$, which again raises the question of whether the CATS score is dominated by grade point average, i.e., suggesting that overcoming misconceptions held by weaker students (as measured by GPA) is difficult.

Furthermore it is unclear that the CATS is the best indicator of progress in our course because the CATS questions are conceptual and not procedural. While we would like to believe that procedural use of simulation tools to investigate behavior of statics problems leads to conceptual understanding of static principles - and in fact we attempt to ask questions in the modules that emphasize concepts - we have not yet verified this with the CATS or any other evidence. Furthermore, some of the concepts that we test in our modules are different than the concepts in the CATS.

It is also difficult to assign absolute meaning to the scores on the projects. The average grades on the projects are less varied by discipline, possibly due to the fact that the projects were completed in groups of 3-4 in which disciplines were mixed. However, a number of important trends were observed, including:

- many students (at least 50\%) resisted using the spreadsheet and used in minimally; we were surprised by the number of students who chose to do a number of "side calculations" manually and then enter these numbers into the spreadsheet, rather than performing them directly in the spreadsheet; students who did this were at a general disadvantage to answer some of the more conceptual questions that required a variation in parameters to illustrate trends in behavior.

- a significant number of students were uncritical in accepting the values of their answers; for example, in Module 2, several students reported displacements that were more than 2 orders of magnitude too great; a generalization of this uncritical attitude is the belief that "computers are always right";

- an interesting misconception was discovered in Module 3: many students believed that the stresses would be higher at the top of the post than at the bottom because the peak wind force intensity occurred at the top of the post.

We also distributed a detailed 25 question survey at the end of the semester to inquire about students' impressions of the course. At total of 71/146 students completed the survey, including $24 / 49$ in the target Civil Engineering cohort. We provide a summary of the key responses of this cohort as they are of most interest to our project. 
Question 1 (open-ended) on the survey asked "In general, what concepts or skills do you think your instructors wanted you to learn with the projects?". After reading and coding the responses, we discovered that 10 students identified basic statics concepts, 5 identified advanced concepts from mechanics of materials, 12 identified some aspect of critical thinking or direct reference to simulation, and 10 identified something related to professional practice, realistic problemsolving, or group work [note that the total number of responses here, 37, exceeds the number of respondents, 24, because some students' answers corresponded to multiple codes].

Questions 2-6 were closed-form questions that asked students to react to certain statements. Table 3 provides a summary of these questions and responses.

\begin{tabular}{|c|c|c|c|c|c|}
\hline $\begin{array}{l}\text { Statement } \rightarrow \\
\text { Response: }\end{array}$ & $\begin{array}{l}\text { 2. "The projects } \\
\text { introduced me to } \\
\text { realistic aspects of } \\
\text { real engineering } \\
\text { projects and } \\
\text { design problems". }\end{array}$ & $\begin{array}{l}\text { 3. "The projects } \\
\text { required me to } \\
\text { think creatively } \\
\text { and/or to discover } \\
\text { things that were } \\
\text { not explicitly } \\
\text { given". }\end{array}$ & $\begin{array}{l}\text { 4. "The projects } \\
\text { helped me to learn } \\
\text { basic concepts of } \\
\text { statics". }\end{array}$ & $\begin{array}{l}\text { 5. "The projects } \\
\text { gave me a good } \\
\text { preview of the next } \\
\text { course in } \\
\text { Mechanics of } \\
\text { Materials". }\end{array}$ & $\begin{array}{l}\text { 6. "I did not like } \\
\text { the projects } \\
\text { because they } \\
\text { added new } \\
\text { concepts to the } \\
\text { course that are not } \\
\text { normally part of } \\
\text { Statics; I would } \\
\text { rather wait until } \\
\text { Mechanics of } \\
\text { Materials to learn } \\
\text { these concepts". }\end{array}$ \\
\hline Strongly agree & 18 & 12 & 18 & 15 & 0 \\
\hline Somewhat agree & 4 & 10 & 4 & 6 & 2 \\
\hline Neutral & 2 & 2 & 2 & 3 & 7 \\
\hline Somewhat disagree & 0 & 0 & 0 & 0 & 9 \\
\hline Strongly disagree & 0 & 0 & 0 & 0 & 6 \\
\hline Overall average & 3.67 & 3.42 & 3.67 & 3.50 & 1.21 \\
\hline
\end{tabular}

Overall, in considering the responses to Questions 1-6, it appears that the students have at least some understanding of our objectives, and respond favorably.

We also probed student opinions about the use of the spreadsheet. When asked "List what you think are both the advantages and disadvantages of using the spreadsheet in this or a similar course", many responses (25) indicated that the spreadsheet is efficient and/or prevents errors; a lesser number of responses (6) seemed to recognize the larger value of being able to able to vary parameters to understand system behavior.

We asked several additional questions about the use of the spreadsheet in a closed format. The student responses here are overall favorable, although this somewhat contradicts their reluctance 
to use the spreadsheet in the projects. Several students indicated that they were not familiar with the spreadsheet and that there was a learning curve required to get accustomed to using it. Table 4 summarizes the results of student attitudes with respect to the spreadsheet.

\begin{tabular}{|c|c|c|c|c|c|}
\hline $\begin{array}{l}\text { Statement } \rightarrow \\
\text { Response: }\end{array}$ & $\begin{array}{l}\text { 11. "Because I did } \\
\text { not have to do } \\
\text { calculations by } \\
\text { hand, the } \\
\text { spreadsheets } \\
\text { allowed me to } \\
\text { focus my attention } \\
\text { on understanding } \\
\text { the concepts and } \\
\text { the meaning of the } \\
\text { results". }\end{array}$ & $\begin{array}{l}\text { 12. "When I used } \\
\text { the spreadsheets I } \\
\text { felt uncomfortable } \\
\text { because I felt that } \\
\text { I should have } \\
\text { been doing the } \\
\text { calculations by } \\
\text { hand instead". }\end{array}$ & $\begin{array}{l}\text { 14. "The } \\
\text { spreadsheets } \\
\text { allowed me to } \\
\text { solve my problems } \\
\text { in an organized } \\
\text { manner and } \\
\text { allowed me to } \\
\text { correct errors } \\
\text { more easily". }\end{array}$ & $\begin{array}{l}\text { 15. "In future } \\
\text { classes, I intend to } \\
\text { use spreadsheets } \\
\text { more often, even if } \\
\text { the professor does } \\
\text { not mention it, } \\
\text { because they will } \\
\text { help me to be } \\
\text { more efficient". }\end{array}$ & $\begin{array}{l}\text { 16. "As a result of } \\
\text { this class, I have } \\
\text { increased my } \\
\text { understanding of } \\
\text { why computer } \\
\text { tools are essential } \\
\text { to the engineering } \\
\text { design process". }\end{array}$ \\
\hline Strongly agree & 12 & 0 & 17 & 11 & 18 \\
\hline Somewhat agree & 4 & 6 & 4 & 7 & 3 \\
\hline Neutral & 5 & 8 & 3 & 5 & 3 \\
\hline Somewhat disagree & 1 & 4 & 0 & 1 & 0 \\
\hline Strongly disagree & 2 & 6 & 0 & 0 & 0 \\
\hline Overall average & 2.96 & 1.58 & 3.58 & 3.17 & 3.63 \\
\hline
\end{tabular}

Finally, another set of questions asked students what they thought about the level of effort required for this class, and whether the effort was worth it. Nearly all students in the Civil Engineering cohort (23/24) reported that the class required above average effort, and most students (15/24) reported that the effort was worth it (similar results were reported by the nonCE students).

\section{Discussion and Conclusions}

In implementing this project we believe that our project is headed in the right direction, but that some important modifications are necessary. We perhaps overestimated the students' ability to use the spreadsheets without explicit instruction; we will address this in the next semester by being both more explicit with our instruction and expectations. We also believe that it is necessary to be more explicit in explaining some techniques that we expect, such as the skill to use the spreadsheet to vary parameters to understand system behavior and make design choices. We feel from our experience that some students really did cross a threshold of mature use where they did use the spreadsheet to critique answers and make informed design decisions. But a 
number of students had problems ranging from the mechanics of the spreadsheet to being uncritical or over-accepting of the results.

The quantitative performance data thus far collected does not demonstrate any learning gains as a result of our methodology. In particular, it is not clear whether the CATS is the right tool to measure learning gains as a result of our modules. Furthermore, it appears that the CATS scores need to be adjusted to account for GPA and math grades. Moreover, it is simply too early in the project to know the subsequent performance of the targeted students in the sequel courses Mechanics of Materials I, Mechanics of Materials II, and Structural Analysis. We are hopeful that in the longer range we will, in fact, see a difference in student performance among the cohort of students who took Statics and Mechanics of Materials with the modules developed by our project.

Finally, next semester (Spring 2013) will be the first introduction of new modules in the Mechanics of Materials I course. Some of these modules will strategically build off of the modules introduced in statics, whereas others will be new. We plan, in particular, to introduce at least one module that incorporates the use of finite element analysis software. While we believe that spreadsheets serve an important introduction to the idea of simulation in Statics, it is important to expose students to other engineering software that can handle more elaborate types of problems.

\section{Acknowledgement}

This material is based upon work supported by the National Science Foundation (TUES Program) under Grant No. 1044866. The authors gratefully acknowledge this support.

\section{Bibliography}

1. Jonassen, D.H., J. Strobel, and C.B. Lee. "Everyday Problem Solving in Engineering: Lessons for Engineering Educators", Journal of Engineering Education, Vol. 95, No. 2, April 2006.

2. Donowa, A., C. Martin, and C. White. "Re-Engineering Engineering: Teaching Students How to Think Critically". Proceedings of the ASEE Annual Conference and Exposition, Honolulu, HI, June 2007.

3. Gorman, M.E., L.G. Richards, W.T. Scherer, and J.K. Kagiwada. "Teaching Invention and Design: MultiDisciplinary Learning Modules”, Journal of Engineering Education, April 1995.

4. Marra, R.M., B. Palmer, and T.A. Litzinger. "The Effects of a First-Year Engineering Design Course on Student Intellectual Development as Measured by the Perry Scheme", Journal of Engineering Education, Vol. 88, No. 3, July 1999.

5. Prince, M.J. and R.M. Felder. "Inductive Teaching and Learning Methods: Definitions, Comparisons, and Research Bases", Journal of Engineering Education, Vol. 95, No. 2, April 2006. 
6. Wilcyznski, V. and S.M. Douglas. "Integrating Design Across the Engineering: Curriculum: A Report From the Trenches", Journal of Engineering Education, Vol. 84, No. 3, July 1995.

7. C. Papadopoulos, A. Santiago Román, G. Portela Gauthier, R. Marín Ramírez, P. Pacheco Roldán. "NSF Poster: Leveraging Simulation Tools to Deliver Ill-Structured Problems: Enhancing Student ProblemSolving Ability in Statics and Mechanics of Materials". Proceedings of the ASEE Annual Conference and Exposition, San Antonio, TX, June, 2012.

8. J. Papadopoulos, C. Papadopoulos, and V. Prantil. "A Philosophy of Integrating FEA Practice throughout the Undergraduate ME/CE Curriculum". Proceedings of the ASEE Annual Conference and Exposition, Vancouver, Canada, June, 2011. 